\title{
Ex situ conservation programmes in European zoological gardens: Can we afford to lose them?
}

\author{
Spartaco Gippoliti
}

Received: 28 October 2011/Accepted: 1 February 2012/Published online: 11 February 2012

(C) Springer Science+Business Media B.V. 2012

\begin{abstract}
The role of ex situ activities for the conservation of biodiversity, and of zoos and aquaria in particular, is open to continuing debate. The present note highlights the conservation breeding potential of zoological gardens and aquaria in the European union, but it also recognises the lack of a convincing scientific and legal framework that encourages ex situ activities for 'exotic' species. If ex situ programmes are considered essential for global biodiversity conservation, the EU should not limit itself to regulating zoos through the zoo directive, but should actively promote and support their ex situ conservation activities.
\end{abstract}

Keywords Biodiversity convention $\cdot$ Zoos $\cdot$ Breeding facilities $\cdot$ Reintroductions

\section{Introduction}

The advent of the Convention on Biological Diversity (CBD) in 1993 was an important step in the history of nature conservation. The CBD was also crucial in recognising the importance of integrating in situ efforts with ex situ projects, and zoos were officially recognised among the institutions dedicated to captive propagation for conservation. Actually, article 9 of the CBD requires signatory parties to "Adopt measures for the ex situ conservation of components of biological diversity, preferably in the country of origin of such components" (Glowka et al. 1994).

As a signatory of the CBD, the European union encourages ex situ activities for native, strictly protected species listed in Annexes IV and V of the habitat directive, and produced an EC zoos directive (22/1999) to oblige zoos and aquaria to adopt a relevant conservation role, consistent with the CBD's requirements (Rees 2005).

It appears that while a number of EU-financed LIFE projects included "captive breeding" among their activities, the active participation of the zoo and aquarium community to European biodiversity conservation has been so far negligible on the whole,

S. Gippoliti $(\bowtie)$

Viale Liegi 48A, 00198 Roma, Italy

e-mail: spartacolobus@hotmail.com 
although notable exceptions exist as in the case of the European mink Mustela lutreola and the bearded vulture Gypaetus barbatus breeding programmes (Anderegg et al. 1984; Maran et al. 2009). As a result there is the paradoxical situation of several breeding (and restocking) programmes, often of popular and charismatic species, managed completely outside the zoo world. Examples only from Italy include Apennine chamois Rupicapra pyrenaica ornata, Apennine hare, Lepus corsicanus, otter Lutra lutra, Egyptian vulture Neophron percnopterus (Gippoliti 2004) and so on.

\section{European zoos and global biodiversity}

However, the main issue raised by this paper concerns the contribution to global biodiversity conservation by European zoos. To our knowledge, no concern has been previously manifested and discussed for the 'parochial' approach posed by ex situ activities as recognised in the $\mathrm{CBD}$, that undoubtedly seems to overlook the importance of non-native taxon populations in European zoos and elsewhere, as is also noted, but not discussed, by Stanley-Price (2005). This issue is of critical relevance for many European institutions, which have a tradition of long-term commitments to biodiversity conservation in non-European countries. Examples of exotic species, owing their survival to ex situ programmes outside their natural range, are continuously growing (Arabian oryx Oryx leucoryx, scimitar-horned oryx Oryx dammah, Kihansi spray toad Nectophrynoides asperginus). Several European zoos have long-established relationships with foreign countries and serve a key role in those countries' national conservation strategies (Peter and Adler 1995; Hatchwell and Rübel 2007). In the last decade, the European Association of Zoos and Aquaria (EAZA, with more than 300 members totalling about 130 million visitors annually) launched several conservation campaigns and financed field projects, mostly of global relevance.

'Permeability' of national borders in ex situ conservation is required by the absence of geographic overlap between the present location of most world zoos and aquaria with biodiversity hotspots, both at the global and the continental level (Gippoliti and Amori 2007a). It may also prevent costly duplications of 'ex situ' programmes dedicated to species occurring in several countries (i.e. non-endemics). Furthermore, the dispersion of ex situ populations among several holders has several advantages, especially in the case of long-term maintenance programmes for long-living vertebrates, often originating from politically unstable regions of the world (see Fig. 1). There is one more reason for supporting ex situ activities outside range countries and this is the real risk of the misuse of scarce resources in financially poor, biodiversity-rich countries that should, ideally, give priority to in situ activities (Gippoliti and Carpaneto 1997). It has been correctly argued that sources of animals for reintroduction should originate from breeding centres in native countries rather than zoos (Stanley-Price and Soorae 2003). However, zoos can collectively furnish valuable resources prior to reintroductions, and afterward contribute to maintain viable populations or at least precious genetic material (Iyengar et al. 2007; Russello et al. 2007), by continuing to maintain a managed stock as an insurance policy. The latter contribution may help to lowering costs of ex situ programmes. Good examples are provided by the black-footed ferret Mustela nigripes, Mexican wolf Canis lupus baileyi, red wolf Canis rufus and California condor Gymnogyps californianus programmes, all in the US and all incorporating both breeding centres and zoos (i.e. Ralls and Ballou 2004; Jackowski and Lockhart 2009). 

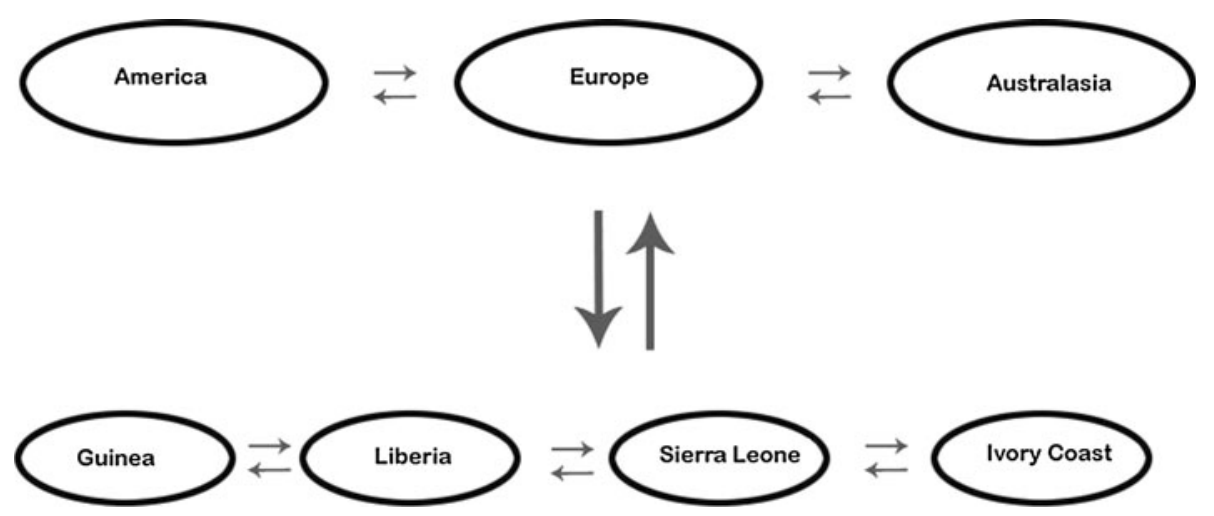

Fig. 1 Schematic representation of an international ex situ breeding programme for a threatened species (pygmy hippopotamus, Choeropsis liberiensis, a species endemic of west African rain forest). For geographic reasons, the programme should be coordinated by European zoos. Zoos in affluent countries should help zoos in the countries of origin to maintain the species to foster public awareness locally and to increase management and husbandry standards

While EU zoo regulation asks zoos to fulfil a conservation and scientific role, funds are generally available within EU countries only for conservation of native species, specifically those included in the habitat and birds directive.

If EU legislation, lack of resources and CBD force zoos to concentrate exclusively on threatened native or continental species, is this a satisfactory achievement for global biodiversity? A number of studies already shows a bias of conservation interest and resources allocation toward threatened species found in industrialised countries (Amori and Gippoliti 2000; Griffiths and Pavajeau 2008; Brito and Oprea 2009).

So far, the immense popularity of European zoos (and the patchy support of governments at local level) has allowed the availability of limited resources to be directed toward international conservation projects. The zoo community seems quite eager to contribute their expertise and facilities to recent biodiversity emergencies such as those concerning amphibians (Pavajeau et al. 2008) and freshwater turtles (Turtle Conservation Fund 2002). Furthermore, there is increasing evidence of the importance of many longterm captive populations for retaining historical levels of genetic diversity in threatened taxa such as lion Panthera leo, tiger Panthera tigris, leopard Panthera pardus, and brown bear Ursus arctos (Barnett et al. 2006; Burger and Hemmer 2006; Gippoliti and Mejaard 2007; Luo et al. 2008; Calvignac et al. 2009). The great number of zoos found inside the EU and the existing high degree of collaboration already existing within EAZA members represent collectively a unique resource to partially counteract the current global biodiversity crisis. Although support to ex situ institutions in developing countries is already taking place (Durrell et al. 2007), and even considering that it may be cheaper to maintain breeding groups of threatened species in the country of origin, it is unlikely that the gap with richer countries could be completely filled in the near future, especially in terms of space availability. This seems quite a different situation from botanical gardens, where tropical institutions may, if adequately financed and improved, furnish ex situ spaces (as seed banks) for a considerable proportion of their endemic plants (Guerrant et al. 2004) and should be recognised in ex situ conservation policies. 
There are already good models of international cooperative breeding programmes for threatened tropical animal species where ownership is maintained by the country of origin (i.e. lion tamarins Leontopithecus spp. cfr. Mallinson 2001).

However, as zoos and aquaria are increasingly dependent on revenue from visitors for their self-maintenance, species selection is constrained more and more by public preference rather than objective conservation criteria (Ratajszczack 2008), to the point that aberrant coloured individuals such as white lions Panthera leo and pythons Python spp.of no conservation value-are becoming commoner in European zoos. Several studies have already stressed the biased composition of zoo collections towards popular species, such as some large python species among the boids (Marešova and Frynta 2007) and colourful parrots (Frynta et al. 2010). It is predictable that as fewer species are maintained in ex situ institutions - a trend due to both economic and animal welfare reasons-competition for zoo space will become more severe, with threatened but non-charismatic species destined to lose (Lernould et al. 2003; Backer 2007). It should be noted also that the creation of large-sized satellite facilities by urban zoos, inaugurated by the Zoological Society of London with the opening of a zoological park at Whipsnade in 1932, is almost ceased decades later. Should ex situ conservation be a good argument to restart the planning of satellite zoos, perhaps also through the creation of consortia of two or more institutions?

\section{A prematurely buried Ark paradigm?}

It is interesting to note that in the last decade captive breeding is not being seen as the only, nor the most relevant, function of zoos and aquaria in the conservation arena (Maunder and Byers 2005). With the abandonment of the so-called 'ark paradigm' (Bowkett 2009), the zoo and aquarium world has assumed a more politically correct role in the environmental arena and urbanised western societies but, paradoxically, seems to distance itself from the unique role it naturally has as an ex situ genetic bank. The selection of species by zoos is becoming freer from immediate conservation concerns (i.e. IUCN red list status), authorising de facto a broad number of considerations in collections planning. The fact that zoos globally house circa $15 \%$ of threatened tetrapods only (Conde et al. 2011) is also due to the current emphasis on in situ conservation and feasibility of short-term reintroductions (Balmford et al. 1996). Gippoliti and Amori (2007a) called for a more long-term and geographically broader approach to establish ex situ priorities, considering conservation status at global level and phylogenetic distinctiveness. Even for existing coordinated breeding programmes, demographic analyses have evidenced severe problems in assuring long-term viability for a large percentage of them (Kaumanns et al. 2000; Backer 2007; Lees and Wilken 2009). Calls for more investment in breeding facilities has been made, otherwise zoos will be not able to maintain viable populations for both exhibition and conservation (Conway 2007; Vince 2008). The recent collapse of vulture populations in India (Green et al. 2004) highlights how captive populations of relatively common species can suddenly become precious from a conservation point of view. Zoos have limited resources, and they cannot hope to comply with all their tasks without external help. On the other hand, and despite the growing importance of environmental issues in political agenda, biodiversity loss continues unabated, and the number of taxa in need of serious $e x$ situ programmes increases (i.e. Mitu mitu, Silveira et al. 2004) while for others it is already too late (i.e. the baiji Lipotes vexillifer, Turvey et al. 2007). The recent extinction in the wild of the northern white rhinoceros Ceratotherium simus cottoni could represent greater 
loss if the recent proposal for raising it to species level is accepted (Groves et al. 2010). Taxonomic revisions is one factor possibly rendering still greater the threat status of biodiversity globally (Gippoliti and Amori 2007b). It is argued that zoos and aquaria should not gave up their 'ark' role while environmental deterioration proceeds at an alarming rate (Conway 2011).

If the European union is interested in maintaining a leading role in the environmental arena, legislative support for international programmes of European ex situ institutions has to be urgently identified, with the aim, for instances, to finance facilities destined exclusively for the captive propagation of globally threatened taxa. Otherwise, ex situ activities for an increasing number of threatened species, other than a handful of charismatic mega vertebrates, are inevitably destined to fail.

Acknowledgments I wished to thank several colleagues for sharing ideas and opinions; they are C. Lees, J.-M. Lernould, A. Kitchener, H. Schram, K. Kawata, and R. Wirth.

\section{References}

Amori G, Gippoliti S (2000) What do mammalogists want to save? Ten years of mammalian conservation biology. Biodivers Conserv 9:785-793

Anderegg R, Frey H, Muller HU (1984) Reintroduction of the bearded vulture or lammergeyer (Gypaetus barbatus aureus) to the Alps. Int Zoo Yearb 23:35-41

Backer A (2007) Animal ambassadors: an analysis of the effectiveness and conservation impact of ex situ breeding efforts. In: Zimmermann A, Hatchwell M, Dickie L, West C (eds) Zoos in the 21st century. Catalyst for conservation? Cambridge University Press, pp 139-154

Balmford A, Mace GM, Leader-Williams N (1996) Designing the ark: setting priorities for captive breeding. Conserv Biol 10:719-727

Barnett R, Yamaguchi N, Barnes I, Cooper A (2006) Lost populations and preserving genetic diversity in the lion Panthera leo: implications for its ex situ conservation. Conserv Genet. doi:10.1007/ s10592-005-9062-0

Bowkett AE (2009) Recent captive-breeding proposals and the return of the ark concept to global species conservation. Conserv Biol 23:773-776

Brito D, Oprea M (2009) Mismatch of research effort and conservation in avian conservation biology. Trop Conserv Sci 2:353-362

Burger J, Hemmer H (2006) Urgent call for further breeding of the relic zoo population of the critically endangered barbary lion (Panthera leo leo Linnaeus 1758). Eur J Wildl Res 52:54-58

Calvignac S, Hughes S, Hanni C (2009) Genetic diversity of endangered brown bear (Ursus arctos) populations at the crossroads of Europe, Asia and Africa. Diver Distrib 1-9. doi:10.1111/j.14724642.2009.00586.x

Conde DA, Flessness N, Colchero F, Jones OR, Scheuerlein A (2011) An emerging role of zoos to conserve biodiversity. Science 331:1390-1391

Conway W (2007) Entering the 21st century. In: Zimmermann A, Hatchwell M, Dickie L, West C (eds) Zoos in the 21st century. Catalyst for conservation? Cambridge University Press, Cambridge, pp 12-21

Conway W (2011) Buying time for wild animals with zoos. Zoo Biol 30:1-8

Durrell L, Anderson DE, Katz AS, Gibson D, Welch CR, Sargent EL, Porton I (2007) The Madagascar fauna group: what zoo cooperation can do for conservation. In: Zimmermann A, Hatchwell M., Dickie L, West C (eds) Zoos in the 21st century. Catalyst for conservation? Cambridge University Press, Cambridge, pp 275-286

Frynta D, Lišková S, Bültmann S, Burda H (2010) Being attractive brings advantages: the case of parrot species in captivity. PLoS ONE 5(9):e12568. doi:10.1371/journal.pone.0012568

Gippoliti S (2004) Captive breeding and conservation of the European mammal diversity. Hystrix It J Mamm 15:35-53

Gippoliti S, Amori G (2007a) Beyond threatened species and reintroduction: establishing priorities for conservation and breeding programmes for European rodents in zoos. Int Zoo Yearb 41:194-202

Gippoliti S, Amori G (2007b) The problem of subspecies and biased taxonomy in conservation lists: the case of mammals. Folia Zool 56:113-117 
Gippoliti S, Carpaneto GM (1997) Captive breeding, zoos, and good sense. Conserv Biol 11:806-807

Gippoliti S, Mejaard E (2007) The Javan leopard: a neglected opportunity for zoos? Control Zool 76:53-55

Glowka L, Synge H, Burhenne-Guilmin F (1994) A guide to the convention on biological diversity. IUCN, Gland

Green RE, Newton I, Shultz S, Cunningham AA, Gilbert M, Pain DJ, Pradash V (2004) Diclofenac poisoning as a cause of vulture population declines across the Indian subcontinent. J Appl Ecol 41:793-800

Griffiths RA, Pavajeau L (2008) Captive breeding, reintroduction, and the conservation of amphibians. Conserv Biol 22:852-861

Groves CP, Fernando P, Robovshý J (2010) The sixth rhino: a taxonomic re-assessment of the critically endangered northern white rhinoceros. PLoS ONE 5(4):e9703. doi:10.1371/journal.pone.0009703

Guerrant EO, Havens K, Maunder M (eds) (2004) Ex situ plant conservation: tools for conserving wild populations. Island Press, Washington D.C

Hatchwell M, Rübel A (2007) The Masoala rainforest: a model partnership in support of in situ conservation in Madagascar. In: Zimmermann A, Hatchwell M, Dickie L, West C (eds) Zoos in the 21st century. Catalyst for conservation? Cambridge University Press, Cambridge, pp 192

Iyengar A, Gilbert T, Woodfine T, Knowles M, Diniz M, Brenneman RA, Louis EE, Maclean N (2007) Remnants of ancient genetic diversity preserved within captive groups of scimitar-horned oryx (Oryx dammah). Mol Ecol 16:2436-2449

Jackowski DS, Lockhart M (2009) Reintroducing the black-footed ferret Mustela nigripes to the great plains of north America. Small Carnivore Conserv 41:58-64

Kaumanns W, Schwitzer C, Klumpe K, Schmid P (2000) How are primate breeding programmes doing? An overview and preliminary analysis. In: Rietkerk F, Hiddinga B, Brouwer K, Smits S (eds) EEP yearbook 1998/99. EAZA Executive Office, Amsterdam, pp 448-460

Lees CM, Wilken J (2009) Sustaining the Ark: the challenges faced by zoos in maintaining viable populations. Int Zoo Yearb 43:6-18

Lernould J-M, Heckel J-O, Wirth R (2003) More participants needed for Philippine spotted deer conservation programme. EAZA News 43:12-13

Luo S-J, Johnson WE, Martenson E, Antunes A, Martelli P, Uphyrkina O, Traylor-Holzer K, Smith J, O'Brien SJ (2008) Subspecies genetic assignments of worldwide captive tigers increase conservation value of captive populations. Curr Biol 18:592-596

Mallinson JJC (2001) Saving Brazil's atlantic rainforest: using the golden-headed lion tamarin Leontopithecus chrysomelas as a flagship for a biodiversity hotspot. Dodo 37:9-20

Maran T, Podra M, Polma M, Macdonald DW (2009) The survival of captive-born animals in restoration programmes-case study of the endangered European mink Mustela lutreola. Biol Conserv 142:1685-1692

Marešova J, Frynta D (2007) Noah's ark is full of common species attractive to humans: the case of boid snakes in zoos. Ecol Econ 64:554-558

Maunder M, Byers O (2005) The IUCN technical guidelines on the management of ex situ populations for conservation: reflecting major changes in the application of ex situ conservation. Oryx 39:95-98

Pavajeau L, Zippel KC, Gibson R, Johnson K (2008) Amphibian ark and the 2008 year of the frog campaign. Int Zoo Yearb 42:24-29

Peter WP, Adler JH (1995) Allwetter zoo, Munster: wildlife conservation activities in Vietnam. Int Zoo Yearb 34:130-135

Ralls K, Ballou JD (2004) Genetic status and management of California condors. The Condor 106:215-228

Ratajszczack R (2008) Disappearing animals: what's next? Eaza News 64:31-32

Rees PA (2005) Will the EC zoos directive increase the conservation value of zoo research? Oryx 39:128-131

Russello MA, Hyseni C, Gibbs JP, Cruz S, Marquez C, Tapia W, Velensky P, Powell JR, Caccone A (2007) Lineage identification of Galápagos tortoises in captivity worldwide. Anim Conserv 10:304-311

Silveira FL, Olmos F, Long AJ (2004) Taxonomy, history, and status of the Alagoas curassow, Mitu mitu (Linnaeus, 1766), the world's most threatened cracid. Ararajuba 12:125-132

Stanley-Price MR (2005) Zoos as a force for conservation: a simple ambition-but how? Oryx 39:109-110

Stanley-Price MR, Soorae PS (2003) Reintroductions: whence and whither? Int Zoo Yearb 38:61-75

Turtle Conservation Fund (2002) A global action plan for conservation of tortoises and freshwater turtles. Strategy and funding prospectus 2002-2007. Conservation International and Chelonian Research Foundation, Washington D.C

Turvey ST, Pitman RL, Taylor BL et al (2007) First human-caused extinction of a cetacean species? Biol Lett 3:537-540

Vince M (2008) Making the case for off-exhibit bird facilities. EAZA News 64:40-41 